\title{
ANALYSIS OF THE BEST THERAPEUTIC ALTERNATIVE FOR INTRACRANIAL DURAL ARTERIOVENOUS MALFORMATIONS
}

\author{
César de Paula Lucas', Mirto N. Prandini², José Guilherme Mendes Pereira Caldas³
}

\begin{abstract}
The material for this rese ard consisted of 93 patients with dural arteriovenous malformations (DAVMs) who were studied re trospectively with regards to therapeutic success and failure, who had undergone either neurosurgery, or embolization or a combination of both methods and whose disease was located in the cavernous sinus, the superior sagittal sinus, the transverse-sigmoid sinus of the anterior fossa and the tentorium. Thus, it was possible to arrive at the following conclusions: treatment of the DAVMs must be indicated, jointly, by an interventionist neuroradiologist and a neurosurgeon; DAVMs of the transversesigmoid sinus were better treated when a combination of both methods was used; DAVMs of the tentorium were also better treated with a combined method; the endovascular method ensured only a $50 \%$ chance of therapeutic success for DAVMs of the superior sagittal sinus; DAVMs of the cavernous sinus are better treated when the endovascular method was used with a transvenous approach, relative to the transarterial approach.
\end{abstract}

KEY WORDS: dural arteriovenous malformation, endovascular therapy, neurosurgical therapy.

\begin{abstract}
Análise da melhor alternativa terapêutica para malformações arteriovenosas durais intracranianas
RESUMO - O material utilizado consistiu de 93 pacientes portadores de malformações arteriovenosas durais (MAVDs) estudados re t rospectivamente em relação ao sucesso e ao fracasso terapêutico submetidos aos métodos neurocirúrgico ou endovascular ou, ainda, combinação entre ambos, em que a doença se localizou nas regiões do seio cavernoso, do seio sagital superior, do seio transverso-sigmóide, da fossa anterior e do tentório. As conclusões foram as seguintes: o tratamento das MAVDs deve ser indicado pelo neurorradiologista intervencionista e pelo neurocirurgião, conjuntamente; as MAVDs do seio transverso-sigmóide foram melhor tratadas através do método combinado; as MAVDs do tentório foram melhor tratadas através do método combinado; as MAVDs do seio sagital superior tratadas por método endovascular asseguraram apenas 50\% de sucesso terapêutico; as MAVDs do seio cavernoso são melhor tratadas por método endovascular empregando-se a via transvenosa quando comparadas com a via transarterial.
\end{abstract}

PALAVRAS-CHAVE: malformação arteriovenosa dural, método endovascular, método neurocirúrgico.

Dural arteriovenous malformations (DAVMs) a re rare and represent $10 \%$ to $15 \%$ of all intracranial arteriovenous malformations ${ }^{1-5}$. DAVMs are complex lesions that need to be evaluated carefully so that the best therapeutic option can be determined, particularly when their biphasic behavior is considered ${ }^{6,7}$. Most DAVMs have a benign behavior and it is sometimes possible to observe spontaneous regression ${ }^{1}$. DAVMs, however, may also present with an aggressive neurological course or a fatal cerebral hemorrhage ${ }^{1}$. A thorough understanding of the angiographic aspects of DAVMs including their pattern of venous drainage, the occurrence of major sinus thrombosis, the presence of leptomeningeal drainage, and the presence of dysplastic venous aneurysms, can help predict a patient's clinical outcome and the natural history of the disease. Left untreated, a DAVM of the anterior fossa or of the tentorial apex demonstrate up to $91 \%$ chance of hemorrhage. If a decision is made to treat DAVMs, regardless of the type of procedure, the goal of treatment needs to be the total obliteration of the lesion. Otherwise, rec ruitment of collateral flow and continued risk of hemorrhage are likely events.

A variety of treatment strategies for DAVMs

Federal University of São Paulo, Escola Paulista de Medicina, São Paulo SP, Brazil: ${ }^{1} \mathrm{MD}$, PhD, Neurosurgeon of the Neurological Institute of Goiânia GO, Brazil; ${ }^{2} \mathrm{MD}$, PhD, Neurosurgeon and Adjunct Professor of the Federal University of São Paulo; ${ }^{3} \mathrm{MD}$, PhD, Neuroradiologist of the University of São Paulo.

Received 15 October 2004, received in final form 18 February 2005. Accepted 8 April 2005.

Dr. César de Paula Lucas - Av. 136 n²76 / apto 1100 / Setor Marista - 74180-040 Goiânia GO - Brasil. E-mail: cesar.lucas@uol.com.br 
a re off e red in the literature, including ligature of the feeding arteries, coagulation or excision of the nidus and venous drainage, transarterial, or transvenous embolization, compression of the vessels in the neck, infusion of estrogen into the external carotid art e ry, electrot h rombosis of the affected sinus, conventional radiotherapy, and stere otactic radiosurge ry. Despite the wide variety of therapeutic options, few have achieved anatomic and clinical cure.

The objective of this study is to clarify the best therapeutic alternative among the three most frequently used methods listed in the literature: endovascular, neurosurgery and a combination method.

\section{METHOD}

This work undertook to carry out a retrospective analysis of 93 patients with intracranial dural arteriove nous malformation. Eight of these patients were treated at the Instituto de Neurologia de Goiânia (GO), 68 were treated at the Teaching Hospital of the School of Medicine of the University of São Paulo (SP), two at the Federal University of São Paulo (SP). Results for the remaining 15 patients had already been published in the journal Neurosurge ry, in 19977. The study covered the period from January $1^{\text {st }}$ to July $30^{\text {th }}, 2003$. All cases were approved by the Ethical Committee of the respective Institution.

The authors found 93 patients harboring DAVM distributed in 5 regions: $32(34,5 \%)$ at the cavernous sinus; $26(28 \%)$ at the transverse-sigmoid sinus; $20(21,5 \%)$ at tentorium; $13(14 \%)$ at the superior sagittal sinus; and $2(2 \%)$ of DAVM of the anterior fossa.

All 93 patients had angiography done in at least six cranial vessels (external and internal carotid and vert ebral) both before and after the treatment in order to study both arterial irrigation and venous drainage.

The group as a whole received either endovascular or neurosurgical therapy. Those patients with DAVM associated to pial AVM, vein of Galen malformation, scalp arteriovenous fistula, direct carotid-cavemous fistulae, arteriovenous fistula of the foramen magnum with medullarydrainage, and medullary AVM and arteritis were excluded from the study.

Patients who met the inclusion criteria were divided into three groups, according to the therapeutic method used: Group A: patients with DAVMs who only received surgical treatment; Group B: patients with DAVMs who only received endovascular treatment; Group C: patients with DAVMs who received a combined tre atment (endovascular and surgical).

Patients who achieved both clinical and angiographic cure were considered successful cases. Any other result combination was considered therapeutic failure. The patients were followed for at least three months.

\section{Group A}

In this group, four patients underwent coagulation and resection of the compromised drainage vein ${ }^{8}$ and in one patient the compromised venous sinus was skeletonized ${ }^{5}$. These techniques were used for fistulas with up to three pedicles and for fistulas with four or more pedicles, respectively.

1) Coagulation and resection of the vein with com promised drainage - The four patients of this group presented DAVM containing, at the most, three vascular pedicles extending towards the region of the fistula. These patients received general anesthesia and were referred to a craniotomy juxtaposed to the location of the DAVM, which was dissected. The aim was to identify the site where the feeding artery was connected to the drainage venous system. Following this procedure, the venous structure was coagulated and resected or, in the case of dysplastic venous systems at a greater risk of perioperative hemorrhage, metal clips were used to block the flow.

2) Skeletonization of the compromised venous sinus - The only patient in this group had a DAVM comprised of four vascular pedicles extending towards the region of the fistula. This patient received general anesthesia and was referred to a craniotomy juxtaposed to the location of the DAVM, and the compromised venous sinus was exposed. It was then skeletonized according to the surgical technique proposed by Lucas et al. ${ }^{5}$.

\section{Group B}

In this group the endovascular technique was used in all the patients. In 29 individuals the transarterial approach was used, in 39, the transvenous approach was chosen and for 7 patients, treatment consisted of a combined transarterial and transvenous approach. The patients were administered general anesthesia for selective catheterization of six cranial vessels, according to the technique described by Seldinger ${ }^{9}$. Embolization was performed with: polyvinyl alcohol (PVA) particles, a mixture of n-isobutyl cyanoacrylate and lipiodol ${ }^{\circledR}$, free microcoils or coils with electrolytic detachment mechanisms, also called Guglielmi detachable coils (GDCs).

\section{Group C}

In this group, the 13 patients received the endovascular treatment first and then the neurosurgical treatment. For 11 of these patients, the transarterial approach was used, for one the transvenous approach was preferred and for the remaining patient, a combined approach was used. After the method failed, the 13 patients underwent neurosurgery and, in 11 individuals the technique described by Lucas et al. was used ${ }^{5}$, while in two patients technique described by Thompson et al. was preferred ${ }^{8}$.

Statistical method

For the purpose of this study, Student's t test was 
used to test the uniformity of the groups with regards to age; the chi-square test was used to test the association between two variables which were analyzed with regards to quality; and the Fisher exact test was used to also test the association in terms of quality. A $p$ value of less than $0.05(p<0.05)$ was considered statistically significant.

\section{RESULTS}

The therapeutic techniques used, namely, the neurosurgical method (group A), the endovascular method (group B) and the combined method (group C) for DAVMs of the five regions (cavernous sinus, transverse-sigmoid sinus, superior sagittal sinus, anterior fossa and tentorium) chosen for the purpose of this study, were studied in detail. Firstly, the three methods used for all the patients were taken into consideration, on an equal basis. Table 1 illustrates the success and the failure for each of the adopted methods. A systematic comparison of the methods, two by two, with the fisher exact test, made it possible to conclude that the combined method (group C) was superior to the endovascular method used alone (group $B)(p=0.0014)$. The combined method (group $C$ ) was responsible for a $100 \%$ therapeutic success rate, compared to $80 \%$ for the neuro s u rgical method (group A) and $57 \%$ for the endovascular method (group B). Those results notwithstanding, it was not possible to identify significant differences between the neurosurgical method (group A) and the endovascular method (group B) or even between the neurosu rgical method (group A) and the combined one (group C).

Table 2 analyzes the three treatment options, with the exception of the patients with DAVM of the cavernous sinus, as most of them had been treated with the endovascular method only. It was then possible to conclude that the combined method (group C) was better than the endovascular method used alone (group $B)(p=0.0029)$. We were not able to demonstrate any significant differences between the other methods. The combined method (group C) was responsible for a 100\% therapeutic success rate, compared to $80 \%$ for the neurosurgical method (group A) and $58 \%$ for the endovascular method (group B). Those results notwithstanding, it was not possible to identify significant differences between the neurosurgical method (group A) and the endovascular method ( $g$ roup $B$ ) or even between the neuro s u rgical method (group A) and the combined one (group C).

The authors also studied the instances of therapeutic success and failure for the three methods adopted and for each one of the regions includ-

Table 1. Success and failure rates for the three methods in this 93-patient popula tion.

\begin{tabular}{lccccccc}
\hline & \multicolumn{7}{c}{ Dural arteriovenous malformation in the five regions } \\
\cline { 2 - 7 } & \multicolumn{2}{c}{ Group A } & \multicolumn{2}{c}{ Group B } & \multicolumn{2}{c}{ Group C } & \\
& $\mathrm{N}$ & $\%$ & $\mathrm{~N}$ & $\%$ & $\mathrm{~N}$ & $\%$ & Total \\
\hline Success & 4 & 80 & 43 & 57 & 13 & 100 & 60 \\
Failure & 1 & 20 & 32 & 43 & - & - & 33 \\
Total & 5 & 100 & 75 & 100 & 13 & 100 & 93 \\
\hline
\end{tabular}

$\mathrm{N}$, number; $\mathrm{p}=0.0014$

Table 2. Success and failure rates for the three methods excluding the 32 patients with dural arteriovenous malformation of the cavernous sinus.

\begin{tabular}{lccccccc}
\hline & \multicolumn{7}{c}{ Dural arteriovenous malformation in the four regions } \\
\cline { 2 - 7 } & \multicolumn{2}{c}{ Group A } & \multicolumn{2}{c}{ Group B } & \multicolumn{2}{c}{ Group C } & \\
\hline Success & $\mathrm{N}$ & $\%$ & $\mathrm{~N}$ & $\%$ & $\mathrm{~N}$ & $\%$ & Total \\
Failure & 4 & 80 & 25 & 58 & 13 & 100 & 42 \\
Total & 1 & 20 & 18 & 42 & - & - & 19 \\
\hline & 5 & 100 & 43 & 100 & 13 & 100 & 61 \\
\hline
\end{tabular}

$\mathrm{N}$, number; $\mathrm{p}=0.0029$ 
Table 3. Success and failure rates for the three methods in patients with dural arteriovenous malformation of the transverse-sigmoid sinus, tentorium and superior sagittal sinus.

\begin{tabular}{lcccccccccccc}
\hline & \multicolumn{3}{c}{ Transverse-sigmoid sinus } & \multicolumn{3}{c}{ Tentorium } & \multicolumn{3}{c}{ Superior sagittal sinus } \\
& \multicolumn{2}{c}{ Success } & \multicolumn{2}{c}{ Failure } & Success & Failure & \multicolumn{2}{c}{ Success } & Failure \\
& $\mathrm{N}$ & $\%$ & $\mathrm{~N}$ & $\%$ & $\mathrm{~N}$ & $\%$ & $\mathrm{~N}$ & $\%$ & $\mathrm{~N}$ & $\%$ & $\mathrm{~N}$ & $\%$ \\
\hline Group A & - & - & - & - & - & - & 1 & 100 & 3 & 100 & - & - \\
Group B & 15 & 71,5 & 6 & 28,5 & 6 & 43 & 8 & 57 & 4 & 50 & 4 & 50 \\
Group C & 5 & 100 & - & - & 5 & 100 & - & - & 2 & 100 & - & - \\
Total & 20 & - & 6 & - & 11 & - & 9 & - & 9 & - & 4 & - \\
\hline
\end{tabular}

$\mathrm{N}$, number; $\mathrm{p}$ tentorium $=0.0397$

Table 4. success and failure rates for the transarterial and trans venous approaches in patients with dural arteriovenous mal formation of the cavernous sinus.

\begin{tabular}{lccccc}
\hline & \multicolumn{4}{c}{ Cavernous sinus } \\
\cline { 2 - 5 } & $\begin{array}{l}\text { Transarterial } \\
\text { approach }\end{array}$ & \multicolumn{2}{c}{$\begin{array}{c}\text { Transvenous } \\
\text { approach }\end{array}$} \\
\hline Success & N & $\%$ & N & $\%$ & Total \\
Failure & 4 & 100 & 11 & 39 & 15 \\
Total & 4 & 100 & 28 & 100 & 32 \\
\hline
\end{tabular}

$\mathrm{N}$, number, $\mathrm{p}=0.0383$

ed in the study, with the exception of those patients with DAVM of the anterior fossa because of the small incidence (two cases only).

Transverse-sigmoid sinus - The patients in this $g$ roup (group A) did not receive neurosurgical treatment alone. In spite of evidence suggesting that the combined method (group C) (five patients successfully operated on and no failures) is superior to the endovascular method (group B) (21 patients who underwent embolization as the only treatment, with a $71.5 \%$ rate of success), there were no significant differences between both methods (Table 3).

Tentorium - In this location it was possible to detect a significant difference between the endovascular method (group B) and the combined one (group C) $(p=0.0397)$. The combined method (group C) ensures a 100\% therapeutic success rate against only $43 \%$ for the endovascular method ( $g$ roup B). The neuro s u rgical method was not successful for the only patient studied (Table 3).
Superior sagittal sinus - In this location it was not possible to detect a significant difference between the three methods, in view of the small number of events (Table 3 ). However, the results do not point towards the use of the endovascular method (group B), since only four (50\%), among the eight patients treated, were considered cured, acco rding to the clinical and angiographic parameters. Both the neurosurgical treatment method (group A) and the combined method resulted in therapeutic success for all the patients assigned to these techniques.

Cavernous sinus - In the region of the cavernous sinus a different procedurewas adopted, since only the endovascular method was used in all these cases. Therefore for this particular location, the best therapy was chosen on the basis of the a p p roach used: transarterial or transvenous. Table 4 presents the instances of success and failure for both approaches, for DAVMs in this region. It is possible to conclude that there is a significant diffe rence favoring the transvenous over the transarterial approach $(p=0.0383)$. The endovascular treatment method, using the transvenous approach, cured $61 \%$ of the patients, while the transarterial approach resulted in failure for all the patients.

\section{DISCUSSION}

Awad et al. ${ }^{10}$, in their retrospective study of 377 patients with DAVM, found the following distribution with regards to their location: $62.6 \%$ of DAVM of the transverse-sigmoid sinus; $15.6 \%$ of D AVM of the cavernous sinus; $8.4 \%$ of DAVM of the tentorium; $7.4 \%$ of DAVM of the superior sagittal sinus; and $5.8 \%$ of DAVM of the anterior fossa. Brown et al. ${ }^{11}$, while following 54 patients, prospectively, found $45 \%$ of DAVMs of the transverse- 
sigmoid sinus, $20 \%$ of DAVMs of the cavernous sinus, $13 \%$ of DAVMs of the superior sagittal sinus, $12 \%$ of DAVMs of the tentorium and $10 \%$ of DAVMs of the anterior fossa. Cognard et al. ${ }^{12}$, while conducting a retrospective analysis of 258 patients admitted to their institutions, for 18 years, found $50 \%$ of DAVMs of the transverse-sigmoid sinus, $26 \%$ of DAVMs of the cavernous sinus, $12 \%$ of DAVMs of the tentorium, $8 \%$ of DAVMs of the superior sagittal sinus and $4 \%$ of the anterior fossa. Lucas et al. ${ }^{7}$, in their meta-analysis of 263 patients described in the literature, found $31 \%$ of DAVMs of the cavernous sinus, $25.5 \%$ of DAVMs of the transverse-sigmoid sinus, $26.5 \%$ of DAVMs of the tentorium, $11 \%$ of DAVMs of the superior sagittal sinus and $9 \%$ of DAVMs of the anterior fossa. In this study, among the 93 patient population, the authors found $34.5 \%$ of DAVMs of the cave rnous sinus, $28 \%$ of DAVMs of the transversesigmoid sinus, $21.5 \%$ of DAVMs of the tentorium, $14 \%$ of DAVMs of the superior sagittal sinus and $2 \%$ of DAVMs of the anterior fossa. In spite of the $p$ revalence of DAVMs of the transverse-sigmoid sinus in the literature, the results of this study showed that DAVMs of the cavernous sinus are more predominant. However, it was not possible to identify a reason for this fact, except, perhaps for the clinical presentation of the DAVMs of the cavernous sinus (red-eye syndrome). It is visually much more evident than the clinical presentation of the DAVMs of the transverse-sigmoid sinus (pulsatile tinnitus), a fact that may lead to greater diagnostic accuracy. As far as the other regions are conce rned, the results from this study, in terms of distribution, are in agreement with the literature.

This project involved 13 venous systems: the leptomeningeal venous system, the veins of Galen, the vein of Rosenthal, the superior and inferior orbital, the superior sagittal, the transverse-sigmoid, straight, cavernous, interc ave rmous, superior and inferior petrous sinus and the torcular Herophili. The leptomeningeal venous system was present in $60 \%$ of the patients included in this stu$d y$, and was the most frequent drainage system in the DAVM of the superior sagittal sinus, where it was present in $61 \%$ of that population and in $100 \%$ of the DAVMs of the anterior fossa and tentorium, findings which corroborate those reported in the literature ${ }^{6,13,14}$. DAVMs of the superior sagittal sinus are frequently associated to the partial or total thrombosis of a segment, which will cause the venous flow from the sinusal system to be redirected to the leptomeningeal system in a retrograde and hipertensive manner. From this standpoint, any cortical venous pattern can become a victim of this physiopathogenic mechanism, from the small brinding veins to the large hemispheric venous system, such as, for example, the vein of Trollard" ${ }^{15}$. According to King and Mar$\operatorname{tin}^{6}$, DAVMs of the anterior fossa and tentorium have a common characteristic, that is, they are considered critical and require urgent surgical intervention because of the high rate of intracranial h e m o rrhage, which is the result of a drainage system which prioritizes the leptomeningeal system. This finding was confirmed in this study, since $100 \%$ of the individuals with DAVMs of the anterior fossa and tentorium, in this study population, had venous drainage to the cortical system. Piske and Lasjaunias ${ }^{14}$ and Lucas et al. ${ }^{5}$ called our attention to the presence of venous dilation which tended to form an aneurysm in the Galen system. This would not only increase the risk of bleeding but, above all, would create a mass effect with direct compression at the level of the diencephalon, the aqueduct of Sylvius, the region of the lamina quadrigemina, the superior cerebellar peduncle and the cerebellum. This was observed in two patients (Figure).

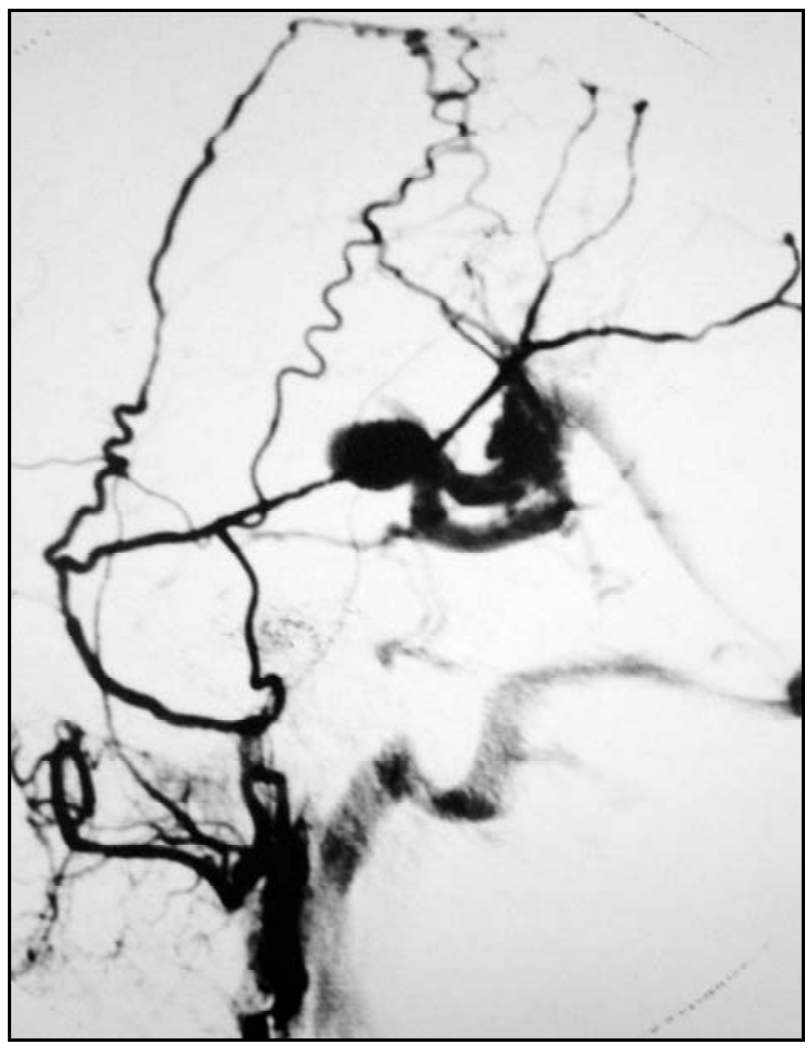

Figure. Cerebral angiography imaging of the encephalon with dural arteriovenous malformation of the tentorium and dys plastic venous dilation compressing the lamina quadrigemina. 
In $88 \%$ of the cases of patients with DAVM of the transverse-sigmoid sinus, venous drainage was to the ipsilateral and contralateral transverse-sigmoid sinus, respectively, in the presence of partial and total venous thrombosis. According to Piton et al. ${ }^{16}$, the presence of total venous thrombosis can cause the venous flow to be re $d$ i rected to the leptomeningeal system. Lalwani et al. ${ }^{17}$ demonstrated that the association between the presence of leptomeningeal venous drainage with partial thrombosis is physiopathogenically due to a previous total thrombosis of the compromised venous sinus, followed by a recanalization of the thrombus, and its total or partial re-opening. Thus, venous drainage to the brain surface would be maintained. Leptomeningeal drainage in the DAVMs of the transverse-sigmoid sinus was present in 54\% of the patients included in this study and most of them flowed toward the Labbé system. Additionally, on DAVMs of the transverse-sigmoid sinus, the redirecting of the venous flow towards the superior petrous sinus took place, preferentially in those patients in whom the site of the thrombosis is upstream from where this sinus emerges, causing a retrograde filling of the system and, as a consequence, of the system of Dandy. This can increase the risk of bleeding and also cause rare symptoms, such as trigeminal neuralgia by compression of the entry zone of the sensitive branches of the fifth cranial nerve $\mathrm{e}^{4,18}$.

In those patients with DAVM of the cavern o us sinus, $72 \%$ presented venous drainage to the superior orbital vein, followed by $44 \%$ to the ipsilateral or contralateral cavernous sinus and $44 \%$ to the leptomeningeal system. These data agree with the study carried out by Barrow et al. ${ }^{19}$, in that a predominance of retrograde drainage to the upper orbital vein was found, which triggering the redeye syndrome ${ }^{20}$. Parkinson ${ }^{21}$ made an anatomical description of the compartmentalization of the cavernous sinus by the trabeculae and independent venous spaces. Yamashita et al. ${ }^{22}$ demonstrated how difficult it was to go around the trabeculae inside this cavernous sinus. This mechanism of anatomic distribution was particularly true in those patients whose partial or total venous thrombosis made catheterization of the several compartments involved in the fistula process especially difficult. As a consequence, therapeutic efficacy was compromised. Another concept that is related to DAVMs of the cavernous sinus, and which was misinterpreted by some authors until the end of the
$80 \mathrm{~s}$, was the connection between these fistulas and a low risk of bleeding ${ }^{23-25}$. Even nowadays, choosing the right therapeutic method is a complicated decision, since both the interventionist ne u roradiologist and the surgeon may have to face technical difficulties which are inherent to the DAVMs and, more frequently than not, an isolated effort from the part of either one of the professionals could be deemed irresponsible.

The primary objective of the treatment, regardless of its nature, is to completely obliterate the lesion, or rather, to achieve clinical and angiographic cure. An incomplete resolution of the DAVMs results in the re cruitment of new feeding vessels which can cause the collateral flow of the leptomeningeal system to be redirected and thus transform a disease with a benign prognosis into something else, which would be the complete opposite $^{5-7,12,15}$. The literature does not bring proof that could serve to clear the role of the surgeon and of the interventionist neuroradiologist, except, pe rhaps in the case of DAVMs located in the anterior fossa and cavernous sinus, and which are treated by surgery and by endovascular techniques, respectively. In this sense if the results obtained from this study do not serve to determine the guidelines for the therapeutic procedure to be adopted, they will serve as a guide, fruit of diligent research, which aims to be simple, and above all, prudent, for the treatment of these lesions.

The treatment and handling of general DAVMs is in constant evolution, especially because of the technological advances in the field of interventionist neuroradiology, and because of the new equipment for superselective catheterization, not to mention the new thromboembolic materials. The determining factor for controlling these lesions is, unquestionably, the choice of the best therapeutic alternative. In these cases, treatment modality can be either endovascular or neurosurgical ${ }^{26}$. However, clinical and angiographic cures are not solely the result of the method chosen. They depend mostly on the correct interpretation of the information related to the angiographic investigation, and which include the presence of total venous thrombosis, leptomeningeal drainage and of dysplastic venous dilation.

\section{Transverse-sigmoid sinus}

DAVMs of the transverse-sigmoid sinus can be t reated either by the neurosurgical or the endovas- 
cular method. However, it is important to note that the treatment of a given DAVM must necessarily include its total resolution, otherwise, the intention to cure creates a more vile and treacherous disease. Yamashita et al. ${ }^{22}$ published a pre viously unheard of case of DAVM of the transversesigmoid sinus which developed after an embolization attempt, of a DAVM of the cavernous sinus, using the transvenous approach. In this study, the endovascular method used alone was capable of curing, angiographically speaking, $71.5 \%$ of the clinical cases of DAVM of the transverse-sigmoid sinus. However, the combined method resulted in $100 \%$ of clinical and angiographic cures. In this location, no patient was treated with the neurosurgical method alone. However, when associated to endovascular therapy, this method was used in those patients whose diseased venous sinus was th rombosed, thereby blocking the advance of microcatheterization. A total thrombosis of the venous sinus was the main limiting factor for therapeutic success, when the endovascular method was used. In this case, and in those patients in whom drainage was anterograde, the compromised sinus was skeletonized, as recommended by Lucas et al. ${ }^{5}, 7$. Another procedurewas the complete resection of the compromised sinus, in the presence of total thrombosis and retrograde resection ${ }^{3,6,26}$.

In view of the clinical and angiographic cure of $71.5 \%$ of the patients, as a result of the endovascular method, we recommend this modality of t reatment as the first therapeutic alternative for DAVMs. The surgical method would be an alternative for those clinical cases, which proved to be refractory to embolization.

\section{Tentorium}

The combined method was the best therapeutic alternative to achieve both the clinic and the angiographic cures of DAVMs of the tentorium $(p<0.05)$. The combined method resolved $100 \%$ of the lesions located in this area, relative to $43 \%$ of successful results achieved with the endovascular method alone, and no success when the surgical method was used. According to King and Mart i $\mathrm{n}^{6}$ and Detwiler et al. ${ }^{15}$ the reduced diameter of the feeding arteries deriving from the posterior cerebral art e ry and superior cerebellar art e ry imposes a limit to the endovascular technique in terms of curing these lesions. The same opinion is shared by Pierot et al. ${ }^{27}$ and Lucas et al. ${ }^{5}$. The endovascu- lar method is effective when one can see the meningeal system which is not derived from the posterior cerebral art e ry and the superior cerebellar arte $y^{5,7}$. When these feeding arteries are present, this method must be restricted and act only as a therapeutic adjuvant, in order to decrease perioperative blood loss. One should then resort to the surgical method, through the skeletonization of the compromised venous sinus.

The natural history of the DAVMs of the tentorium is a poor one, in the sense that these lesions a re frequently associated to leptomeningeal drainage and venous dysplasia. In this study, venous drainage to the cerebral cortex for DAVMs of the tentorium occurred in $100 \%$ of the cases, while a venous aneurysm was present in $25 \%$ individuals. This association increases, significantly, the risk of hemorrhage ${ }^{2,6,14,27}$. The presence of an aneurysminduced dilation of the vein of Galen is equally related to an aggressive natural history ${ }^{6,13,14}$. These DAVMs are located rather deeply, and that constitutes the main limiting factor for achieving clinical and angiographic cures, when the neuros urg ical method is used by itself 5 .

\section{Superior sagittal sinus}

DAVMs of the superior sagittal sinus are rare. In this paper only 13 patients had DAVM in this location. The endovascular therapy by itself was able to cure $50 \%$ of the treated lesions. The neurosurgical method treated all three patients eff $i-$ ciently. The combined method produced clinical and angiographic cure in the two patients listed. In spite of the fact that DAVMs of the superior sagittal sinus are not prevalent, it is possible to note a trend which does not favor the use of the endovascular method alone (eight patients treated and only four cured), especially in those clinical cases which present total thrombosis of the sinus. In this location, the choice of the ideal therapeutic method seems to rest on the individual features of each case, and, naturally, on the data found in the literature and which comprise a partial or total th rombosis of the compromised venous sinus and the presence of cortical drainage and venous aneurysm. However, the frequent association of DAVMs of the superior sagittal sinus with leptomeningeal drainage, normally with a single fistula, (only one pedicle), makes the surgical technique described by Thompson et al. ${ }^{8}$ the first therapeutic option for these cases. 


\section{Cavernous sinus}

Most of the patients with DAVM of the cavernous sinus, in the literature, was treated with the endovascular method. Only a minority of the patients underwent surgery, as the endovascular method failed with them, causing the persistence of the leptomeningeal drainage. Several authors mentioned in their work the fact that the association between leptomeningeal drainage and DAVM of the cavernous sinus was a rare one $e^{6,23,25}$. However, in this study the authors identified $44 \%$ of venous drainage to the cortical system, which generated $12 \%$ of the intracranial hemorrhage episodes.

The analysis of the endovascular method using the transarterial and transvenous approaches in a paired matrix, it was possible to notice that the technique which used the venous approach was superior to that which used the arterial appro ach $(p<0.05)$. That is, all the results for the patients $t$ reated with the transarterial approach only were classified as failures, while for $61 \%$ of the patients, treated with a transvenous approach, theresults we re successful. This information agrees with the experiences of some authors who advocate the transvenous approach as the method of choice to achieve clinical and angiographic cure for DAVMs of the cavernous sinus ${ }^{19,20,22,24}$.

\section{Anterior fossa}

This location is surprisingly rare and the literature contains only 37 reports of patients with DAVM of the anterior fossa ${ }^{6,14,28}$. The recommended treatment in the literature, in these cases, is primarily surgical in nature because of the presence of the feeding anterior and posterior ethmoidal arteries, which branch out from the ophthalmic artery $6,7,28$. This ramification makes for a very difficult endovascular procedure since the possibility of migration of a thromboembolic particle to the ophthalmic artery and from there to the retinal art e ry exposes the patient to the unnecessary risk of amaurosis. Several authors have warned against the risk of thromboembolic material migration when the transarterial approach is used ${ }^{29,30}$. The difficulty does not lie in the approach, but rather on the expertise of the interventionist neuroradiologist. His mastery of the technique will enable him to circumvent this limitation and give him the appropriate clinical and angiographic control. In this case, the recommendation is to use the transve- nous approach, rather than the transarterial approach, in patients with no hemorrhagic events.

Venous drainage of a DAVM of the anterior fossa is commonly done towards the leptomeningeal system, since the anterior ethmoidal arteries, after crossing the cribriform plate, reach the ce rebral cortex thus establishing the formation of a fistula. According to Martin et al. ${ }^{28}$, these DAVMs are constantly involved with cases of intracranial hemorrhage.

\section{CONCLUSION}

The analysis of the material studied in this paper allowed the authors to arrive at the following conclusions:

1. The treatment of DAVMs must be indicated, jointly, by the interventionist neuroradiologist and the neurosurgeon.

2. The neurosurgical method, in combination with the endovascular method resulted in $100 \%$ of clinical and angiographic cure for those patients with DAVM of the tentorium, while the endovascular therapy alone resulted in only $43 \%$ of cure $s$ $(p=0.0397)$.

3. The endovascular method by itself, for DAVMs of the transverse-sigmoid sinus, resulted in a $71.5 \%$ therapeutic success rate. When it was combined with the neurosurgical method, the success rate increased to $100 \%$.

4. The endovascular method by itself, for DAVMs of the superior sagittal sinus, resulted in a $50 \%$ therapeutic success rate. When it was combined with the neurosurgical method, the success rate increased to $100 \%$.

5. The endovascular method with a transvenous approach was shown to be more efficient, relative to the transarterial approach for treating DAVMs of the cavernous sinus ( $p=0.0383$ ). None of the patient treated with the transarterial approach achieved therapeutic success, in contrast with the transvenous approach, which resulted in a $61 \%$ rate of success.

\section{REFERENCES}

1. Olutola PS, Eliam M, Molot M, Talalla A. Spontaneous regression of a dural arteriovenous malformation. Neurosurgery 1983;12:687-690.

2. Grisoli F, Vincentelli F, Fuchs S, et al. Surgical treatment of tentorial arteriovenous malformations draining into the subarachnoid space: report of four cases. J Neurosurg 1984;60:1059-1066.

3. Grady MS, Pobereskin L. Arteriovenous malformations of the dura mater. Surg Neurol 1987;28:135-140.

4. Nabors MW, Azzam CJ, Albanna FJ, Culya AJ, Davis DO, Kobrine AL. Delayed postoperative dural arteriovenous malformations: report of two cases. J Neurosurg 1987;66:768-772. 
5. Lucas $\mathrm{CP}$, Oliveira E, Tedeschi $\mathrm{H}$, et al. Sinus skeletonization: a treatment for dural arteriovenous malformations of the tentorial apex: report of two cases. J Neurosurg 1996;84:514-517.

6. King WA, Martin NA. Intracerebral hemorrhage due to dural arteriovenous malformations and fistulae. Neurosurg Clin N Am 1992;3: 577-590.

7. Lucas CP, Zabramski JM, Spetzler RF, Jacobowitz R. Treatment for intracranial dural arteriovenous malformations: a meta-analysis from the english language literature. Neurosurgery 1997;40:1119-1132.

8. Thompson BG, Doppman JI, Oldfield EH. Treatment of cranial dural arteriovenous fistulae by interruption of leptomeningeal venous drainage. J Neurosurg 1994;80:617-623.

9. Seldinger SI. Catheter replacement of the needle in percutaneous arteriography: a new technique. Acta Radiol 1953;39:368-376.

10. Awad IA, Little JR, Akrawi WP, Ahl J. Intracranial dural arteriovenous malformations: factors predisposing to an aggressive neurological course. J Neurosurg 1990;72:839-850.

11. B rown RD Jr, Wiebers DO, Nichols DA. Intracranial dural arteriovenous fistulae: angiographic predictors of intracranial hemorrhage and clinical outcome in nonsurgical patients. J Neurosurg 1994;81:531-538.

12. Cognard C, Gobin YP, Pierot L, et al. Cerebral dural arteriovenous fistulas: clinical and angiographic correlation with a revised classification of venous drainage. Radiology 1995;194:671-680.

13. Lasjaunias P, Chiu M, Terbrugge K, Tolia A, Hurth M, Bernstein M. Neurological manifestations of intracranial dural arteriovenous malformations. J Neurosurg 1986;64:724-730.

14. Piske RL, Lasjaunias P. Extrasinusal dural arteriovenous malformations: report of three cases. Neuroradiology 1988;30:426-432.

15. Detwiler PW, Lucas CP, Zabramski JM, Mcdougall CG. Cranial dural arteriovenous malformations. BNI Quarterly 2000;16:24-32.

16. Piton J, Guilleux MH, Guibert-Tranier F, Caille JM. Fistulae of the lateral sinus. J Neuroradiol 1984;11:143-159.

17. Lalwani AK, Dowd CF, Halbach VV. Grading venous restrictive disease in patients with dural arteriovenous fistulas of the transverse/sigmoid sinus. J Neurosurg 1993;79:11-15.

18. Lucas CP, Costa V, Costa J, Martins LF, Melo-Souza SE, Raffin CN.
Malformação arteriovenosa dural do seio transverso-sigmóide causando neuralgia trigeminal. Arq Bras Neurocirurg 1999;18:51-54.

19. B a r row DL, Spector RH, Braun LF, Landman JA, Tindall SC, Tindall GT. Classification and treatment of spontaneous carotid cavernous sinus fistulas. J Neurosurg 1985;62:248-256.

20. Teng MMH, Guo WY, Huang CI, Wu CC, Chang T. Occlusion of arteriovenous malformations of the cavernous sinus via the superior ophthalmic vein. Am J Neuroradiol 1988;9:539-546.

21. Parkinson D. Dural arteriovenous malformations. Surg Neurol 1988;29:164-165.

22. Yamashita K, Taki W, Nishi S, et al. Transvenous embolization of dural caroticacavernous fistulae: technical considerations. Neuroradiology 1993;35:475-479.

23. Sergott RC, Grossman RJ, Savino PJ, Bosley TM, Schatz NJ. The syndrome of paradoxical worsening of worsening of dural-cavernous sinus arteriovenous malformations. Ophthalmology 1987;94:205-212.

24. Barnwell SL, Halbach VV, Dowd CF, Higashida RT, Hieshima GH. Dural arteriovenous fistulas involving the inferior petrosal sinus: angiographic findings in six patients. AJNR Am J Neuroradiol 1990;11:511-516.

25. Kurata A, Takano M, Tokiwa K, Miyasaka Y, Yada K, Kan S. Spontaneous carotid cavernous fistula presenting only with cranial nerve palsies. AJNR Am J Neuroradiol 1993;14:1097-1101.

26. Mullan S, Johnson DL. Combined sagittal and lateral sinus dural fistulae occlusion. J Neurosurg 1995;82:159-165.

27. Pierot L, Chiras J, Meder JF, Rose M, Rivierez M, Marsault C. Dural arteriovenous fistulas of the posterior fossa draining indo subarachnoid veins. Am J Neuroradiol 1992;13:315-323.

28. Martin NA, King WA, Wilson CB, Nutik S, Carter LP, Spetzler RF. Management of dural arteriovenous malformations of the anterior cranial fossa. J Neurosurg 1990;72:692-697.

29. Bernini FP, Cioffi FA, Muras I. Arteriovenous shunts between dural branches of the carotid artery and the cavernous sinus. Surg Neurol 1982;18:102-107.

30. Spetzler RF, Modic M, Bonstelle C. Spontaneous opening of large occipital-vertebral artery anastomosis during embolization: case report. J Neurosurg 1980;53:849-850. 